\title{
Ultrastructural changes in the developing chicken cornea following caffeine administration
}

\author{
Kujawa-Hadryś Monika, Tosik Dariusz, Bartel Hieronim \\ Department of Histology and Tissue Ultrastructure, Łódź Medical University, Łódź, Poland
}

\begin{abstract}
Caffeine is one of the most frequently consumed psychoactive substances. It has been known for many years that caffeine at high concentrations exerts harmful effects on both women's and laboratory animals' fertility, moreover it may impair normal development of many organs in the prenatal period. So far there have been few studies performed that demonstrate teratogenic effects of caffeine on structures of the developing eye, particularly the cornea. The aim of the study was to show ultrastructural changes in the developing cornea, as the effect of caffeine administration to chicken embryos. The experimental materials were 26 chicken embryos from incubated breeding eggs. Eggs were divided into two groups: control $(n=30)$ in which Ringer liquid was administrated, and experimental $(n=30)$ in which teratogenic dose of caffeine $3.5 \mathrm{mg} / \mathrm{egg}$ was given. In 36th hour of incubation solutions were given with cannula through hole in an egg shell directly onto amniotic membrane. After closing the hole with a glass plate and paraffine, eggs were put back to incubator. In $10^{\text {th }}$ and $19^{\text {th }}$ day of incubation corneas were taken for morphological analysis with a use of electron microscopy. Administration of caffeine during chicken development causes changes of collagen fibers of Bowman's membrane patterns and of the corneal stroma but it also changes proportion of amount of collagen fibers and of the stromal cells.
\end{abstract}

Key words: cornea, chicken embryo, caffeine, ultrastructure

\section{Introduction}

An eye is a very complex structure that originates from the wall of the diencephalon, the overlying surface ectoderm and cranial neural crest mesenchyme. During the development of an eye two important processes can be distinguished. One is associated with a series of inductive signals that result in the initial establishment of the major components of eye. The other process involves coordinated differentiation of those components. For correct reception of visual impressions, interaction between adjacent elements of eye is necessary [1-5].

Formation of the cornea is an example of a series of inductive stimuli during the eye formation between the lens vesicle and the overlying surface ectoderm. This induction results in the transformation of a typical surface ectoderm to a transparent, multilayered structure composed of complex extracellular matrix and cellular constituents originating from a number of sources.

Correspondence: M. Kujawa Hadrys, Department of Histology and Tissue Ultrastructure, Medical University,

Żeligowskiego 7/9, 90-643 Łódź, Poland;

e-mail: monika.kh@vp.pl
Inductive influence of the lens results in a change in the basal ectoderm cells. The process leads to cells increase in height and their enlargement. Cells begin to secrete collagen types I, II and IX, and this leads to forming a primary stroma of cornea [6]. In the next stage of an early development, the cornea endothelium is formed from the neural crest cells, which are localized around the optic cup and migrate centrally between the primary stroma and the lens capsule. At this point the early cornea consists of an outer epithelium, primary stroma and an inner endothelium. After the corneal endothelium forms a continuous layer, the cells begin to synthesize and secrete large amounts of hyaluronic acid into the primary stroma. Because of its osmotic properties, hyaluronic acid causes the primary stroma enlargement markedly. Migration of cells of neural crest origin to the primary stroma occurs in the next stage of the cornea formation. They proliferate between the layers of collagen fibers. Migration of the cells into the primary stroma ceases when these cells begin to produce hyaluronidase, which causes degradation of large amounts of the hyaluronic acid in the primary stroma. Digestion of the hyaluronic acid results in a decrease of primary stroma thickness. After fibroblasts have been organ- 
ized in the primary stroma, it transforms into the secondary stroma. Fibroblasts participate in a production of stroma collagen fibers. Both epithelial and endothelial cells secrete stromal components compose the remaining layers that constitute the mature cornea, the outer epithelium, the anterior limiting lamina (Bowman's membrane), the posterior limiting lamina (Descemet's membrane) and the endothelium [7]. The final developmental stages during the formation of cornea involve number of changes leading to accomplishment of its total transparency. Initially, degradation of the hyaluronic acid occurs, and causes removal of water from the secondary stroma. The second phase of dehydration is mediated by thyroxine that is secreted into the fetal blood by the maturing thyroid gland. Thyroxine affects sodium ions transportation from the corneal stroma into the anterior chamber of the eye. Water molecules follow the sodium ions, thus completing the total dehydration of the corneal stroma. The final phase in cornea formation involves pronounced change in its radius of curvature in relation to that of the eyeball. These morphogenetic changes allow the cornea to function as an optic center which effectively transmits light rays to the retina $[1,2,3,8-10]$.

Caffeine is a natural alcaloid, derivative of xanthines, which is characterized by three methyl groups (1,3,7-trimethylxanthine). Caffeine is one of the most commonly consumed psychostimulants, and it's a component of such beverages like coffee, tea, cocacola, as well as chocolate. It is also component of numerous drugs, both over-the-counter medications available without special restrictions, e.g. for colds and strong acting drugs i.e. anti-allergic drugs, diuretics or anti-migraine medications [11].

Caffeine crosses the placenta and appears in the amniotic fluid, umbilical cord blood, then in the plasma and urine of the neonate [12,13]. It is a highly metabolized drug with only about $0.5 \%$ to $3.0 \%$ being excreted unchanged with urine. Urine caffeine concentration depends on blood caffeine concentration, caffeine renal clearance and urine flow rate [14]. Since human fetuses have lower levels of enzymes that metabolize caffeine, fetal caffeine blood level depends on its maternal blood concentrations [15]. Caffeine clearance remains essentially unchanged during the first trimester of pregnancy, whereas it is markedly decreased in the second and third trimester. Therefore, the half-life of caffeine in pregnant women is four times longer than in non-pregnant ones (where it amounts to $2.5 \mathrm{~h}$ ), what finally results in increased caffeine blood concentration in pregnant women [16]. Caffeine elimination rates are lower in neonates and fetuses, which results in an observation that a given dose of caffeine causes more effects in the fetus compared to adults.

\section{Materials and methods}

Experiment was performed on chicken embryos from hatching eggs, which were incubated at temperature $37-38^{\circ} \mathrm{C}$ and humidity $50-60 \%$. 26 embryos were examined. Chicken embryos have developed in about $40-60 \%$ of hatching eggs. The hatching eggs were randomly divided into two groups. The first group was the control group. Ringer solution was administered to 30 eggs from this group in $36^{\text {th }}$ hour of incubation (formation stage $9 / 10$, according to Hamburger-Hamilton) [17]. A teratogenic dose of caffeine of $3.5 \mathrm{mg}$ per egg [18] was administered to the consecutive 30 eggs of experimental group. The solutions were administered using a cannule, through a fenestra in the eggshell, directly to the amniotic membrane. After closing the fenestra with a glass plate and paraffin, the eggs were placed back in the incubator. For morphological analysis in electron microscopy corneas were obtained on 10th (formation stage 36 according to Hamburger-Hamilton) and 19 (formation stage 45 according to Hamburger-Hamilton) of incubation. The specimens were fixed in $3.6 \%$ glutaraldehyde for 3 hours, and then rinsed in $0.13 \mathrm{M}$ cacodylic buffer. Post fixation procedure involved contrasting the samples in $2 \%$ osmium tetroxide solution.

Obtained tissues were dehydrated in an increasing alcohol solutions and propylene oxide, then embedded into epoxy resinAraldite. Next ultrathin sections were stained with lead citrate and uranyl acelate and assessed using electron microscope Philips EM 301.

\section{Results}

At the light microscopic level, the reduction in total corneal thickness in the experimental group, in comparison with control groups, both in the 10th as well as in the 19th day of incubation has been noted (Fig. $1 \mathrm{~A}, \mathrm{~B}, \mathrm{C}, \mathrm{D})$. The total corneal thickness increased during the development. In the 10th day of incubation was lower than in 19th day of incubation both in control and experimental groups. Proportions between different layers of the cornea remained preserved in all groups. No apparent differences in a construction of the individual layers of the cornea have been showed between the groups in the respective days of incubation. In all groups anterior epithelium was stratified squamous nonceratinized. Bowman's membrane was visible under it. The corneal stroma was the thickest layer of the cornea. Its width increased between the 10th and 19th day of the development, both in control and experimental groups. In this same time the number of stromal cells was reduced. The number of cells per field of view was higher in experimental groups in comparison to controls. Descemet's membrane was between corneal stroma and the corneal endothelium.

In the cells of corneal anterior epithelium in the control group on day 10, we observed large euchromatic nuclei, transcriptional active nucleoli, large amounts of rough endoplasmic reticulum and mitochondria around the nucleus, numerous polisomes and occurrence of regular, unfolded basement membrane (Fig. 2A). In the experimental group the chromatin seemed denser, nucleus that was spongy in appearance was much smaller and a smaller number of organelles 

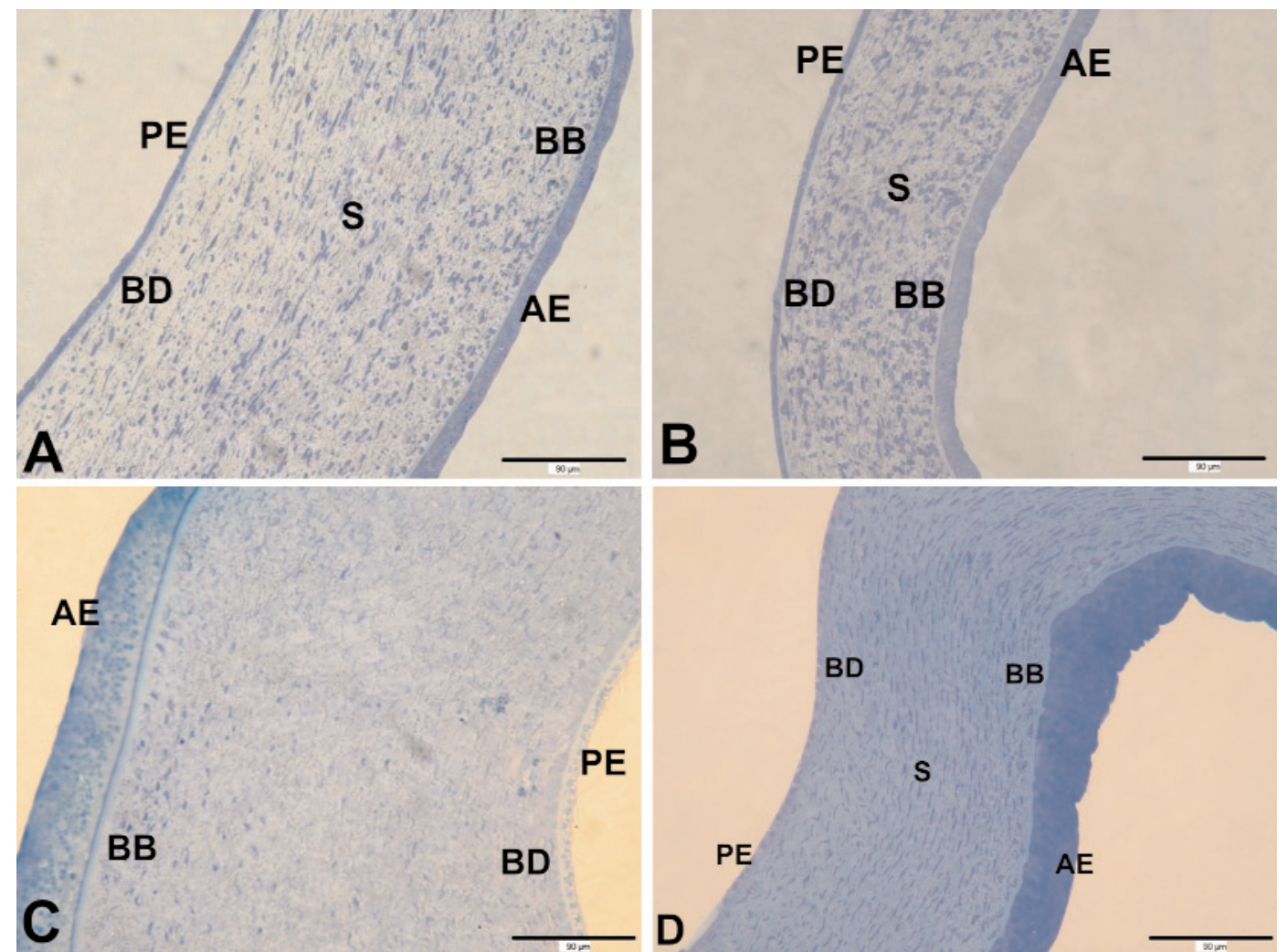

Fig. 1. Semithin sections of cornea. Total thickness of cornea in experimental groups (E10 - 1B, E19 - 1D) decreases in comparison to respective control groups $(\mathrm{C} 10-1 \mathrm{~A}, \mathrm{C} 19-1 \mathrm{C})$. Additionally, stroma width decreases and density of stromal cells is higher in experimental groups (original magnification $\times 200$ ). AE - anterior epithelium, BB - Bowman's membrane, $\mathrm{S}-$ stroma, BD - Descemet's membrane, PE - posterior epithelium.
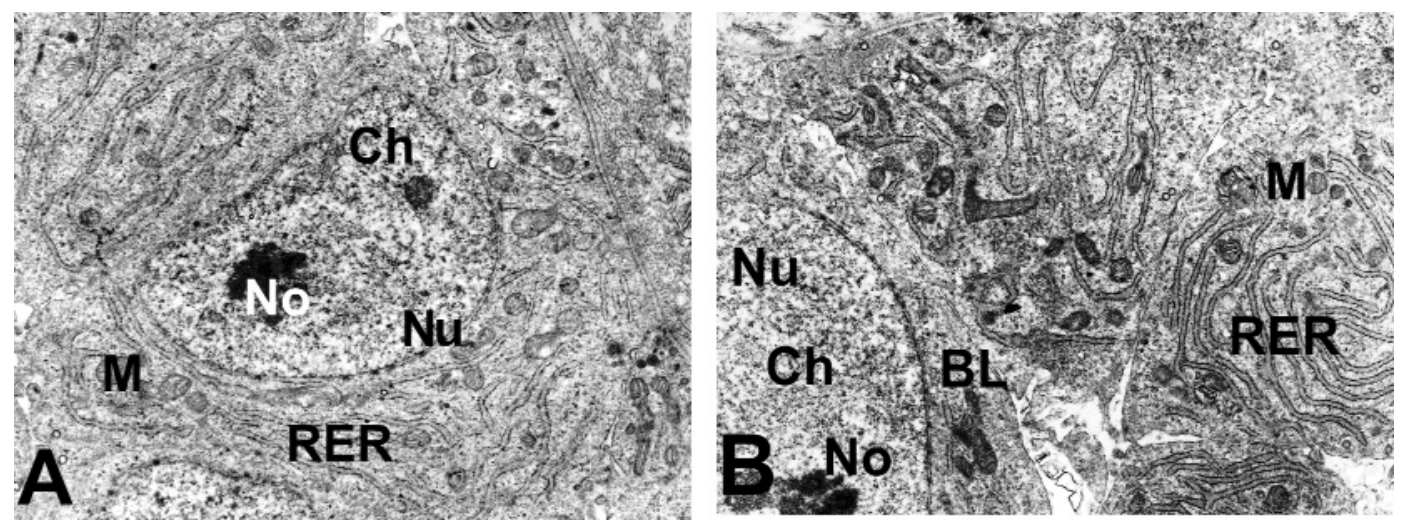

Fig. 2. Corneal anterior epithelium. Incubation day 10. A. The control group (original magnification $\times 21300$ ). B. The experimental group (original magnification x21300). RER- rough endoplasmic reticulum, $\mathrm{M}$ - mitochondria, $\mathrm{Nu}$ - nucleus, No - nucleolus, $\mathrm{Ch}-$ nuclear chromatine, $\mathrm{BL}$ - basal lamina.

(rough endoplasmic reticulum and mitochondria) surrounding the nucleus with the dominating extranuclear localization of the organelles were noted. Similarly to the control group, the basement membrane did not show any folding either (Fig. 2B).

On $10^{\text {th }}$ day, in the corneal stromal cells of control group, we observed the occurrence of elongated, euchromatic nuclei with distinct spongy type nucle- oli, well-developed rough endoplasmic reticulum. Those features indicate high transcriptional activity of stromal fibroblasts. Collagen fibers formed perpendicular laminas (Fig.3A). In the experimental group stromal cells and collagen fibers showed irregular organization. The cell nuclei were large and irregular, nucleoli were more dense and compact. Moreover, rough endoplasmic reticulum cisterns 

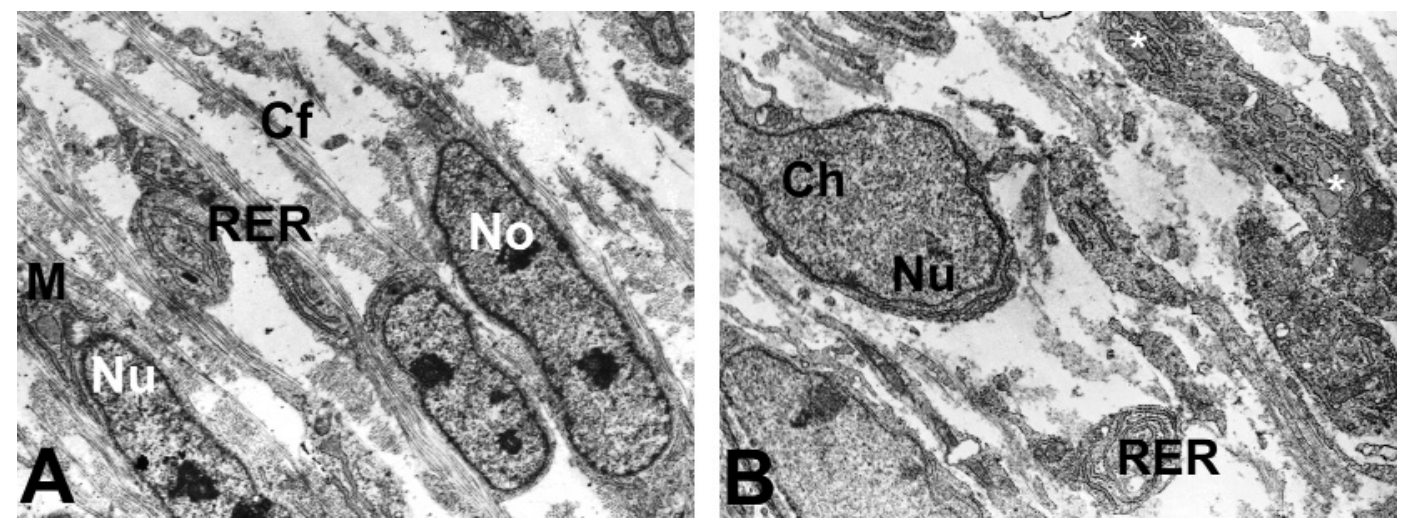

Fig. 3. Corneal stroma. Incubation day 10. A. The control group (original magnification $\times 10200$ ). B. The experimental group (original magnification x17100). RER- rough endoplasmic reticulum, $\mathrm{M}$ - mitochondria, $\mathrm{Nu}$-nucleus, $\mathrm{No}$ - nucleolus, $\mathrm{Cf}-\mathrm{collagen}$ fibers, $\mathrm{Ch}-$ chromatin.
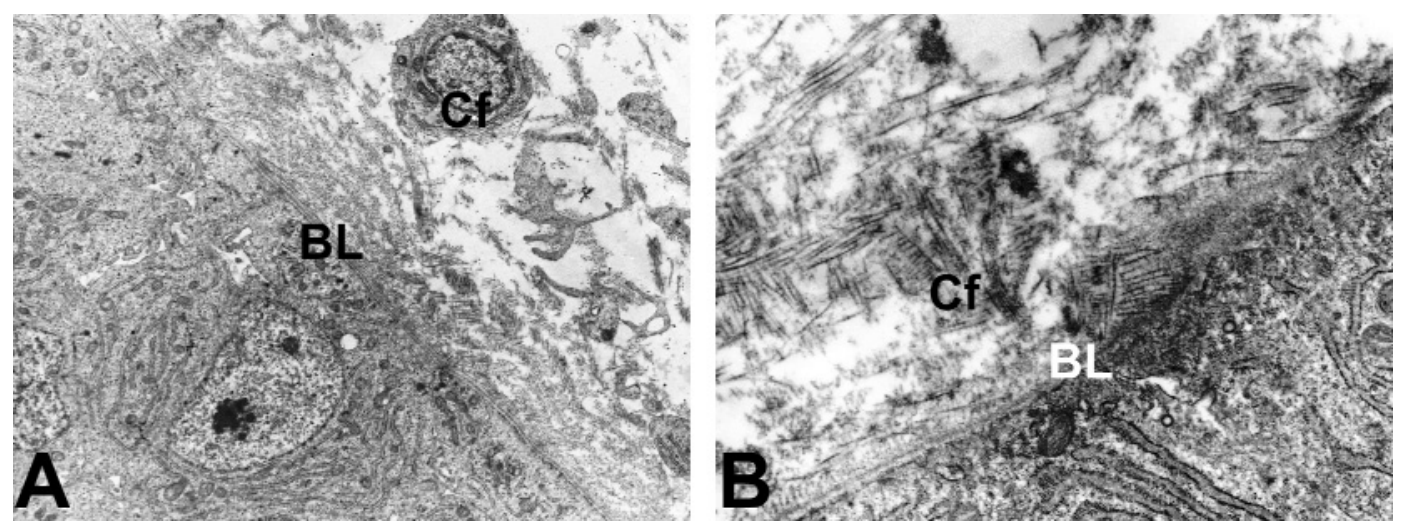

Fig. 4. Bowman's membrane. Incubation day 10. A. The control group (original magnification $\times 10200$ ). B. The experimental group (original magnification x33000). $\mathrm{Cf}$ - collagen fibers, BL - basal lamina.
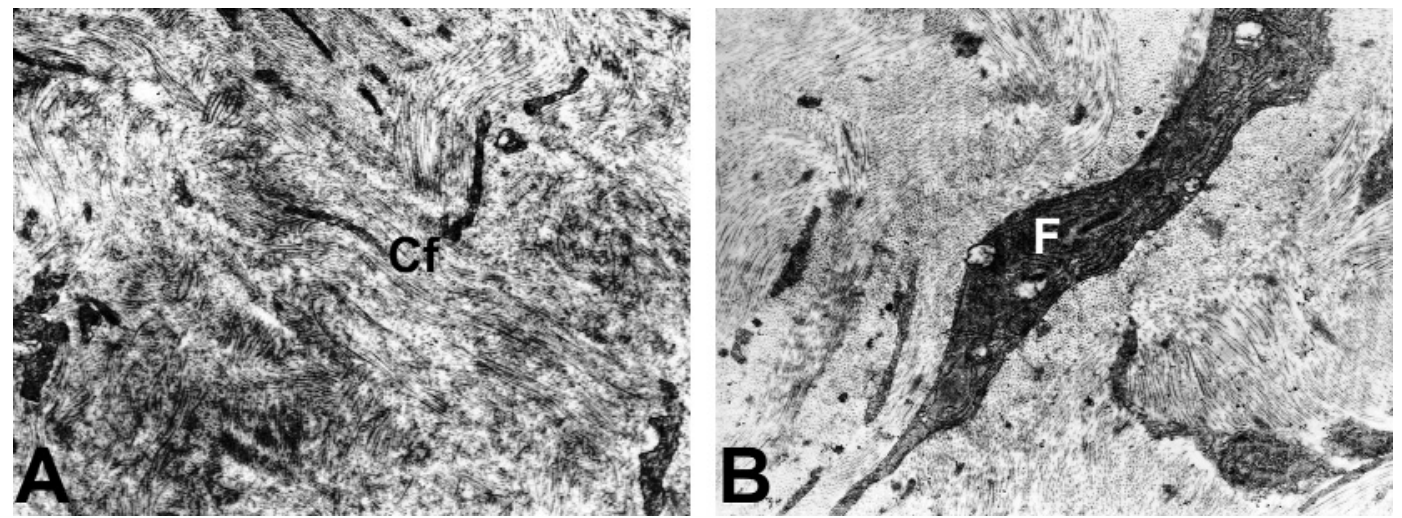

Fig. 5. Corneal stroma. Incubation day 19. A. The control group (original magnification $\times 27300$ ). B. The experimental group (original magnification $\mathrm{x} 21300)$. $\mathrm{Cf}$ - collagen fibers. F - fibroblast.

contained large amount of homogenous content (Fig.3B).

On 10th day, in the control group, we observed a regular herringbone pattern of the short collagen fibers in the control group in the Bowman's membrane, whereas in the experimental group the Bow- man's membrane appeared less regular with slightly blurring outlines of the basement membrane, the fibers were of different length and organized irregularly (Fig. 4 A, B).

On 19th day in the control group we noted numerous processes and marked folding of the basement 
membrane in the anterior epithelium of the cornea. We also discovered a large number of collagen fibers that formed laminae and a small amount of cells and intercellular substance in this group (Fig. 5A). In experimental group much fewer number of collagen fibers boundless with less regular pattern and elongated fibroblasts with rich rough endoplasmic reticulum were observed (Fig. 5B).

\section{Discussion}

Numerous experiments performed on animals have confirmed teratogenic effects of caffeine. Administration of that alkaloid can result in the development of pathological lesions both in eyes and in the whole body system. Kurata et al. experimental studies demonstrate that caffeine induces intraocular hypertension and applied intravenously does not induce changes in aqueous humor flow through the trabeculous meshwork [19]. It has been suggested, reffering to the other investigations of those authors, that caffeine causes intraocular hypertension by inducing changes in the epithelium of the ciliary body [20]. Caffeine administered per os at a dose of $200 \mathrm{mg}$ contributes to a significant decrease in ocular blood flow within an hour following caffeine intake [21]. Moreover, it tends to increase the blood vessel resistance and decrease blood flow in the optic nerve head and choroid-retina. Blood flow decrease can impair the development of the retina [22].

There have been scarce studies performed so far that would demonstrate the harmful effects of caffeine on the cornea and lens. In an experimental study performed by Evereklioglu et al. $[23,24]$, the effect of caffeine administered to pregnant rats during the period of organogenesis in rats (from day 9 through day 20 of gestation) on the formation of neonatal cornea and lens in their offspring was investigated. There were no macroscopic corneal abnormalities in the newborn litters of experimental or control animals. In the group treated with intraperitoneal caffeine $25 \mathrm{mg} / \mathrm{kg}$ /day litters had a normal anterior corneal epithelium, regular stromal collagen fibers, normal Descemet's membrane and a simple regular corneal endothelium. In the remaining experimental groups, caffeine administrated at high doses, over $50 \mathrm{mg} / \mathrm{kg} /$ day, corneal oedema was observed at postnatal day 30 . The lesions were particularly visible in the group with the highest dose of caffeine and those included multilayered endothelial cellular proliferation with hyperchromasia and polymorphism, increased corneal stromal fibroblasts mitotic activity, focal morphological changes, and corneal swelling in the injured areas with irregular and widely separated destructive stromal fibers. At postnatal day 30 , irregularly oriented, vacuolated and polymorphic endothelial cells as well as their agenesis were observed in the same group [24].
Moreover, in those groups histological examinations revealed cataractogenic changes that involved irregularly oriented lens fibers, the occurrence of swollen cortical fiber cells with liquefaction, the presence of prominent epithelial cells lining the posterior lens capsule behind the equator, and retention of the nuclei in the central lens fibers with peripheral eosinophilic degeneration. The occurrence of cataract on slit-lamp biomicroscopic examination at postnatal day 30 was observed in the experimental group, which was treated with caffeine at a dose of $100 \mathrm{mg} / \mathrm{kg} /$ day [23]. Lens formation can be impaired by a toxic injury induced by caffeine consumption in pregnancy and resulting in the development of cataract that is associated with abnormalities in the cells of the developing lens. Degeneration, injury and liquefaction of solid components of the cortical fibers contribute to cortical cataract development [25]. In the initial stages of cataractogenesis occurrence of cortical vacuoles, granules or fissurae can be observed. Degenerated cortical fibers become swollen, which can result in a total fibre liquefaction. Similar changes occurring in the prenatal cataractogenesis in rats have been demonstrated before in experimental studies [26]. In the present study caffeine was administered to a chicken embryos during vesicle formation (stage 9/10 according to HamburgerHamilton). Dose was determined experimentally for a single chicken teratogenic dose- $3.5 \mathrm{mg} / \mathrm{egg}$ [Bruvere H.J. 1983]. Based on several studies, the teratogenic dose of caffeine for certain animal species was found. However, these doses can not be applied to humans, animal studies are a good way to assess the potential effect of caffeine on the human body. The present study focuses on the effect of caffeine on the development of cornea on the ultrastructural level. At the light microscopic level, the reduction in total corneal thickness and stromal thickness in the experimental groups, compared with control groups, both in the $10^{\text {th }}$ as well as in the $19^{\text {th }}$ day of incubation has been noted. Reduction of the relative stromal thickness, the thickest part of the cornea, could suggest the disorder in the structure and arrangement of collagen fibers. In the experimental groups, on the ultrastructural level, arrangement of collagen fibers were irregular and the fibers were considerably fewer than in the control groups. Similarly, Bowman's membrane is characterized by an irregular arrangement of collagen fibers. Also on the light microscope level the thickness of Bowman's membrane is reduced. In the $19^{\text {th }}$ day of incubation in the experimental group smaller number of collagen fibers with irregular laminar arrangement in the corneal stroma and occurrence of abundant rough endoplasm reticulum in the cytoplasm of stromal fibroblasts have been noticed.

The degenerative mechanisms of caffeine still remain hypothetical. Caffeine induces intracellular 
increase in cAMP by inhibiting the activity of phosphodiesterases. The increase in cAMP could affect the growth and development of fetal tissues [27].

It seems that caffeine does not exert harmful effects on development provided its consumption is low and controlled. Because of rapid metabolism of caffeine in human, it is not teratogen. However, high doses of caffeine may increase teratogenic effect of other factors, such as cigarette smoking or alcohol intake [28].

On the basis of the results of numerous studies it can be assumed that women in reproductive period are should limit daily caffeine intake to $5-6 \mathrm{mg} / \mathrm{kg}$, in order to reduce the risk of fertility problems and the occurrence of malformations in their offspring [29].

\section{References}

[1] Bartel H. Embriologia medyczna. Wyd. I., Warszawa: Wydawnictwo Lekarskie PZWL; 2009.

[2] Bartel H. Embriologia. Wyd. 4, Warszawa: Wydawnictwo Lekarskie PZWL; 2004.

[3] Carlson BM. Human Embryology and Developmental Biology. $3^{\text {rd }}$ ed, St. Louis: Mosby; 2004.

[4] Niżankowska MH. Podstawy okulistyki. Wyd. 2, Wrocław: Volumed; 2000.

[ 5] Sadler T. Langman's Medical Embryology. $9^{\text {th }}$ ed, Philadelphia: Lippincott Williams of Wilkins; 2003.

[ 6] Daxer A, Misof K, Grabner B, Ettl A, Fratzl P. Collagen fibrils in the human corneal stroma: structure and aging. Invest Ophthalmol Vis Sci. 1998;39:644-648.

[7] Greiling TMS, Clark JI. The transparent lens and cornea in the mouse and zebra fish eye. Semin Cell Dev Biol. 2008; 19:94-99.

[ 8] Cvekl A, Tamm ER. Anterior eye development and ocular mesenchyme: new insights from mouse models and human diseases. Bioessays. 2004;26(4):374-386.

[9] Ferretti P, Copp A, Tickle C, Moore C. Embryos, genes and birth defects. $2^{\text {nd }}$ ed, London: John Wiley and Sons; 2006.

[10] Schoenwolf GC, Bleyl SB, Brauer PR, Francis-West PH. Larsen's Human Embryology. $4^{\text {th }}$ ed, New York: Churchill Livingstone; 2009.

[11] Graham DM. Caffeine - its identity, dietary sources, intake and biological effects. Nutr Rev. 1978;36:97-102.

[12] Jiritano L, Bortolotti A, Gaspari F, Bonati M. Caffeine disposition after oral administration to pregnant rats. Xenobiotica. 1985; 15:1045-1051.

[13] Kirkinen P, Jouppila P, Koivula A. The effect of caffeine on placental and fetal blood flow in human pregnancy. Am J Obstet Gynecol. 1983;147:939-42.

[14] Bech BH, Obel C, Henriksen TB, Olsen J. Effect of reducing caffeine intake on birth weight and length of gestation: randomised controlled trial. BMJ. 2007;334;409.
[15] Aldridge A, Bailey J, Neims AH. The disposition of caffeine during and after pregnancy. Semin Perinatol. 1981;5:310314.

[16] Knutti R, Rothweiler H, Schlatter C. The effect of pregnancy on the pharmacokinetics of caffeine. Arch Toxicol Suppl. 1982;5:187-192.

[17] Hamburger V, Hamilton HL. A series of normal stages in the development of the chick embryo. J Morphol. 1951;88:49-92.

[18] Bruvere HJ, Nishikawa T, Uno H, Gilbert JE, Gilbert EF. Pulmonary stenosis with ventricular septal defect, common aorticopulmonary trunk, and dextroposition of the aorta: morfologic and qualitative physiologic effect in caffein-treated chick embryos. Teratology. 1983;27:197-206.

[19] Kurata K, Fujimoto H, Tsukuda R, Suzuki T, Ando T, Tokuriki M. Aqueous humor dynamics in beagle dogs with caffeineinduced ocular hypertension. JVMS. 1998;60: 737-739.

[20] Kurata K, Maeda M, Nishida E. Relationship between caffeineinduced ocular hypertension and ultrastructure changes of nonpigmented ciliary epithelial cells in rats. $J$ Toxicol Sci. 1997;22:447-454.

[21] Lotfi K, Grunwald JE. The acute effect of caffeine on the human macular circulation. Invest Ophthalmol Vis Sci. 1991; 32:3028-3032.

[22] Okuno T, Sugiyama T, Tominaga M, Kojima S, Ikeda T. Effects of caffeine on microcirculation of the human ocular fundus. Jpn J Ophthalmol. 2002;46:170-176.

[23] Evereklioglu C, Guldur E, Alasehirli B, Cengiz B, Sari I, Pirbudak L. Excessive maternal caffeine exposure during pregnancy is cataractogenic for neonatal crystalline lenses in rats: a biomicroscopic and histopathologic study. Acta Ophthalmol Scand. 2004;82(5):552-556.

[24] Evereklioglu C, Sari I, Alasehirli B et al. High dose of caffeine administered to pregnant rats causes histopathological changes in the cornea of newborn pups. Med Sci Monit. 2003;9:168-73.

[25] Klintworth GK, Eagle RC. The eye and ocular adnexia. In:Stephen SS(ed). Diagnostic Surgical Pathology. 3rd ed. Philadelphia: Lippincott, Williams and Wilkins; 1999.

[26] Rogers JM, Grabowski CT. Postnatal mirex cataractogenesis in rats: lens action balance, growth and histology. Exp Eye Res. 1984;39:563-573.

[27] Weathersbee PS, Lodge JR. Caffeine: its direct and indirect influence on reproduction. JRM. 1977;19:55-63.

[28] Ross CP, Persaud TV. Cardiovascular primordium of the rat embryo following in utero exposure to alcohol and caffeine. CJC. 1986;2(3):160-163.

[29] Christian MS, Brent RL. Teratogen update: evaluation of the reproductive and developmental risks of caffeine. Teratology. 2001;64:51-78.
Submitted: 5 November, 2009 Accepted after reviews: 22 June, 2010 